\title{
Article
}

\section{Fingerprinting microbiomes towards screening for microbial antibiotic resistance}

Jin, Naifu, Zhang, Dayi and Martin, Francis L

Available at http://clok.uclan.ac.uk/17376/

Jin, Naifu, Zhang, Dayi and Martin, Francis L ORCID: 0000-0001-8562-4944

(2017) Fingerprinting microbiomes towards screening for microbial antibiotic resistance. Integrative Biology, 9 (5). pp. 406-417. ISSN 1757-9694

It is advisable to refer to the publisher's version if you intend to cite from the work. http://dx.doi.org/10.1039/C71B00009]

For more information about UCLan's research in this area go to http://www.uclan.ac.uk/researchgroups/ and search for <name of research Group>.

For information about Research generally at UCLan please go to http://www.uclan.ac.uk/research/

All outputs in CLoK are protected by Intellectual Property Rights law, including Copyright law. Copyright, IPR and Moral Rights for the works on this site are retained by the individual authors and/or other copyright owners. Terms and conditions for use of this material are defined in the policies page.

\section{CLoK}

Central Lancashire online Knowledge www.clok.uclan.ac.uk 

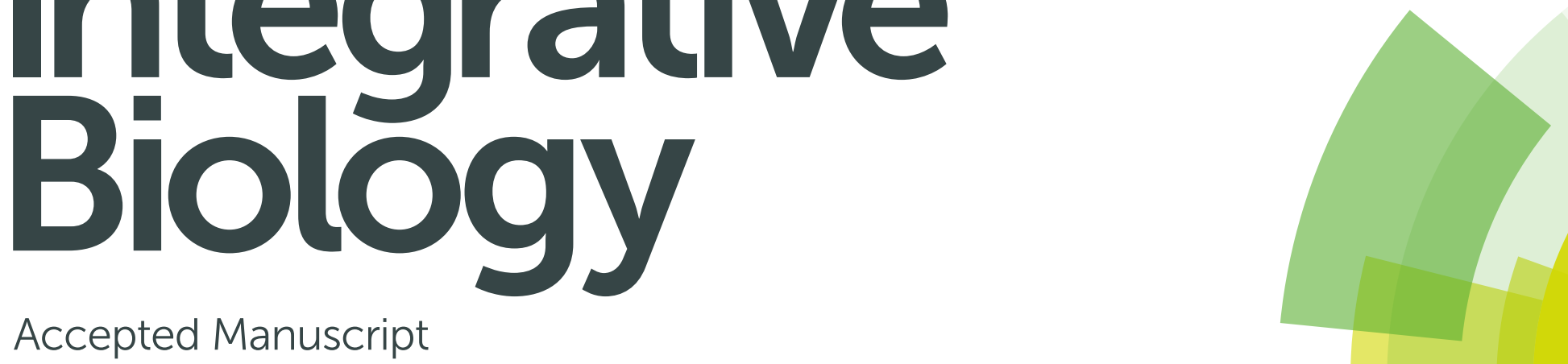

Accepted Manuscript

This article can be cited before page numbers have been issued, to do this please use: N. Jin, D. Zhang and F. L. Martin, Integr. Biol., 2017, DOI: 10.1039/C7IB00009J.

\section{Integrative Biology}

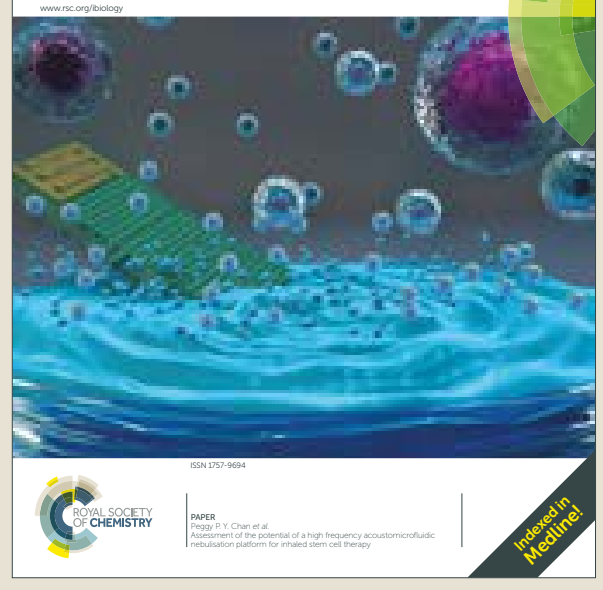

This is an Accepted Manuscript, which has been through the Royal Society of Chemistry peer review process and has been accepted for publication.

Accepted Manuscripts are published online shortly after acceptance, before technical editing, formatting and proof reading. Using this free service, authors can make their results available to the community, in citable form, before we publish the edited article. We will replace this Accepted Manuscript with the edited and formatted Advance Article as soon as it is available.

You can find more information about Accepted Manuscripts in the author guidelines.

Please note that technical editing may introduce minor changes to the text and/or graphics, which may alter content. The journal's standard Terms \& Conditions and the ethical guidelines, outlined in our author and reviewer resource centre, still apply. In no event shall the Royal Society of Chemistry be held responsible for any errors or omissions in this Accepted Manuscript or any consequences arising from the use of any information it contains. 


\section{Insight, innovation, integration}

The introduction of biospectroscopic screening allows rapid in-situ diagnosis of antibiotic resistance in microbiomes as well as real-time detection of population dynamics and determination of genotype flexibility (e.g., HGT process and microbial response to antibiotic pressure) via monitoring phenotype differentiation, which can significantly improve the understanding of antibiotic resistance in the clinical and physical environment. 


\section{Fingerprinting microbiomes towards screening for microbial antibiotic resistance}

Naifu Jin ${ }^{1}$, Dayi Zhang ${ }^{1, *}$, Francis L. Martin ${ }^{2, *}$

${ }^{1}$ Lancaster Environment Centre, Lancaster University, Lancaster LA1 4YQ, UK; ${ }^{2}$ School of Pharmacy and Biomedical Sciences, University of Central Lancashire, Preston PR1 2HE, UK

*Corresponding authors: Dayi Zhang, Email: d.zhang@1ancaster.ac.uk; Francis L Martin, Email: flmartin@uclan.ac.uk 


\begin{abstract}
There is an increasing need to investigate microbiomes in their entirety in a variety of contexts ranging from environmental to human health scenarios. This requirement is becoming increasingly important with emergence of antibiotic resistance. In general, more conventional approaches are too expensive and/or time-consuming and often predicated on prior knowledge of the microorganisms one wishes to study. Herein, we propose the use of biospectroscopy tools as relatively high-throughput, non-destructive approaches to profile microbiomes under study. Fourier-transform infrared (FTIR) or Raman spectroscopy both generate fingerprint spectra of biological material and such spectra can readily be subsequently classed according to biochemical changes in the microbiota, such as emergence of antibiotic resistance. FTIR spectroscopy techniques generally can only be applied to desiccated material whereas Raman approaches can be applied to more hydrated samples. The ability to readily fingerprint microbiomes could lend itself to new approaches in determining microbial behaviours and emergence of antibiotic resistance.
\end{abstract}




\section{Microbiomes and their response to the natural environment}

Microbial communities, including bacteria, archaea, viruses, protists or fungi, play a vital role in many ecosystems. Global carbon cycles in the ocean, for instance, at least $50 \%$ of carbon dioxide is fixed through photosynthesis providing the energy for microbial respiration and reproduction $^{1,2}$. Human health is also highly dependent on microbes since a very abundant mix of bacterial species symbiotically survives within humans and many principal organs are their habitats. The skin surface is the largest habitat with multiple regional variations in cellular architecture and environmental exposures for microbes, where the density of bacteria can reach $10^{7}$ cells per square centimetre ${ }^{3}$. However, bacteria colonizing on external surfaces only count for some $10 \%$ (i.e., $10^{14}$ bacterial cells to $10^{13}$ human cells) while the rest $90 \%$ comprise the commensal microbiome living in the body ${ }^{4-9}$. A majority of these microbial cells exist in the gastrointestinal tract (GIT) and constitute the human intestinal microbiota, which has a concentration of $10^{12} \mathrm{CFU} / \mathrm{g}$ and probably represents one of the densest, most biodiverse and rapidly evolving bacterial ecosystems on earth ${ }^{4-9}$. Another representative example is the microbial flora in the oral cavity as the entrance of the digestive tract; over 500 microorganism species have been identified and can attach to oral surfaces and colonize to form a microbial matrix, e.g., dental plaque or oral biofilm ${ }^{10}$. The dynamics of human host microbial communities account for many diverse phenomena associated with public health issues, e.g., changes in the gut microbial community may be linked to metabolic disorders, obesity and Crohn's disease ${ }^{11}$.

Antibiotics are widely used to treat microbe-induced diseases and are also applied at sub-therapeutic levels via animal feed to maintain meat quality and quantity. Since Sir Alexander Fleming identified penicillin in 1928, the environment has become the primary receiver for most applied antibiotics and their residues via excretion of human and animals ${ }^{12-}$ 18. Currently, antibiotics are ranked as the third most commonly prescribed class of agents, and frequently used in human medicine, agriculture, aquaculture and the agri-food industry, resulting in an enormous amounts of antimicrobial usage ${ }^{19}$. Accordingly, antibiotic misuse may result in a seriously antibiotic-abundant circumstance for microbes as well as humans. Consequently, in response to such environmental stimuli, bacteria acquire the capability of antibiotic resistance, and ultimately superbugs may emerge ${ }^{20}$. It is worth highlighting that microbiota from humans and natural environments are not separated but connected via various routes of exposure. For example, horizontal gene transfer (HGT) allows rapid development of genetic divergence and therefore leads to virulence, antibiotic resistance, and xenobiotic metabolism, spreading through microbe populations inhabiting in human bodies and natural environments ${ }^{21}$. HGT accelerates the spread of antibiotic resistance genes (ARGs) and emergence of superbugs, which is a lethal threat to humans and therefore a major focus of scientific interest ${ }^{22,23}$.

With such growing concerns, ARGs and their relevant mechanisms have been identified in clinical and environmental contexts ${ }^{12-18,24-27}$. Many approaches have been applied to investigate their existence and spread as well as their dynamics within natural microbiota. Herein, we briefly discuss the conventional methods used to determine antibiotic resistance 
and ARGs within the microbial community, both phenotypically and genetically, as well as how biospectroscopy can be applied to fingerprint microbiomes and microbial antibiotic resistance.

\section{Conventional biological approaches to determine microbial antibiotic resistance}

Research into microbial antibiotic resistance primarily uses different techniques and methodologies, generally categorized as function- and molecular-based methods according to focus, i.e., function-based approaches aim at particular behaviour or mechanisms of individual microbes based on their roles or characteristics, while molecular-based approaches target in high-throughput fashion the molecular components within the complex microbiotas.

\subsection{Function-based approaches}

Culturing is the most applied function-based approach to determine microbial response to antibiotics $^{2,28,29}$ due to its inherent merit which is a focus on individual strains, instead of the interrogated complexity and diversity of the whole microbiota ${ }^{30,31}$. Most known antibioticresistant microbes and genes are identified by direct culturing, isolate purification, and further investigation into their resistance profiles ${ }^{25,32,33}$. For example, colonies grown with antibiotics are screened for the presence of antibiotic biomarkers, located on either plasmids or chromosomes ${ }^{33}$. However, $>90 \%$ bacteria are currently unculturable but functional in$s_{i t u}^{34-36}$. Culture-dependent methods are always questioned for their ability to represent the real scenario and for an underestimation of ARG abundance ${ }^{31}$. Some improved techniques, such as stable isotope probing (SIP) and magnetic nanoparticle-mediated isolation, further enumerate the functional fractions, not individual, from the total microbiota ${ }^{37,38}$.

\subsection{Molecular-based approaches}

Instead of targeting microbes with specific functions, molecular-based approaches deal with microbiota as an integrated system by directly extracting biological components. With the rapid development of molecular tools, molecular-based approaches have evolved from polymerase chain reaction (PCR) and denaturing gradient gel electrophoresis (DGGE) to high-throughput sequencing and $\operatorname{Omics}^{31,39,40}$, uncovering ARGs from all the microorganisms within a microbiota, including those uncultured ${ }^{39,41-43}$. Notably, the recent development of Omics, from genomics to proteomics, allows generation of large-scale datasets for cellular components (DNA, RNA, and proteins) compositions, interactions and profiles, yielding a comprehensive database of genetic functions of $\mathrm{ARGs}^{40}$, e.g., isolating novel ARGs from microbial communities of human oral and soil ${ }^{39,44}$. However, molecularbased approaches have an inherent insufficiency in confirming behavioural functions and linking those functions to identities of antibiotic-resistant strains. Meanwhile, as destructive methods of collecting cellular components, molecular-based approaches may not meet the need for in-situ diagnosis of antibiotic resistance in real-time.

\subsection{Which is more important?}

Individual vs. microbiome. It is hard to answer which, single cells or the whole communities, 
needs to be investigated to better understand antibiotic resistance in the microbiome. ARGs and antibiotic resistance mechanisms vary between individuals, implying insight into the single cell may provide more comprehensive information. On the other hand, although individual cells hold their respective ecological niche, they also contribute to the overall function of the microbiome as a whole. Since most microbes are somewhat dormant in the natural environment within developing communities such as mat, sludge or biofilm, it is worth paying more attention for clinical purposes to the response of the microbiome to antibiotics, rather than that of individual cells, i.e., typically, an unnecessary single-cell-level test is required for the diagnosis of diseases. Biofilm, for instance, consists $2 \%$ to $15 \%$ of microorganisms with the remainder being their self-produced matrix of extracellular polymeric substances $(\sim 90 \%)$ secreted by microbes making individual cells stick together and colonize on a surface; this overall community performs functional tasks similar to multicellular organisms for adaptation to environmental changes ${ }^{45-49}$. Extracellular polymeric substances matrix facilitates communication between cells (e.g., such as quorum sensing), maintains biofilm hydration and protects microorganisms against environmental stresses. The chemical composition and structure of extracellular polymeric substances depend on cell species, metabolic activity, nutrient availability, biofilm maturity level and physicochemical conditions. Biofilm formation offers microbes an entirely different lifestyle weighing against the planktonic state providing protection from external exposures (e.g., antibiotics) for the community $^{45-49}$. Recently, the field of single cell study has developed some breakthroughs allowing characterisation and interrogation of particular microbes at reasonable levels ${ }^{50-60}$. However, these remain insufficient to fulfil the need to study microbial interactions within the microbiome and their surrounding environment. Thus, further research into the functionality of the entire microbiome is needed.

Phenotype vs. genotype. Stochasticity in gene expression may induce genetically-identical cells under the same environmental exposures to express significant variation in molecular content and discriminating differences in phenotypic characteristics; this implies cell functions may be altered by non-genetic regulation providing a mechanism for phenotypic and cell-type diversification regardless of genotype ${ }^{61-63}$. Such phenotypic heterogeneity helps microbes survive exposures to antibiotics owing to the fact that a small genetically-identical subset of persistent cells can survive an extended period and get over the exposure time ${ }^{61}$. This phenomenon may bring another challenge regarding in-situ diagnosis of antibiotic resistances of interrogated microbiomes since the phenotype of the microbiome may be unpredictable even under an acknowledged circumstance due to the influence of epigenetic factors ${ }^{64,65}$. Therefore, finding a new approach that can quickly screen the phenotype of a microbiome to determine the in-situ bacterial antibiotic resistance in real-time is urgently required.

\section{A new dawn for biospectroscopy in microbiological research}

\subsection{Principles of biospectroscopy}

Biospectroscopy encompasses a range of techniques that allow the spectroscopic examination 
of biological samples. Such spectroscopic measurements are usually based on electronic transitions and vibrational changes of chemical bonds with spatial resolutions from the microscopic to the macroscopic. These both examine the morphological contrast in biological samples and uncovers elemental or molecular information via further determination ${ }^{66}$. Infrared (IR) or Raman spectroscopy are the two most applied biospectroscopy techniques since the $1960 \mathrm{~s}^{67,68}$.

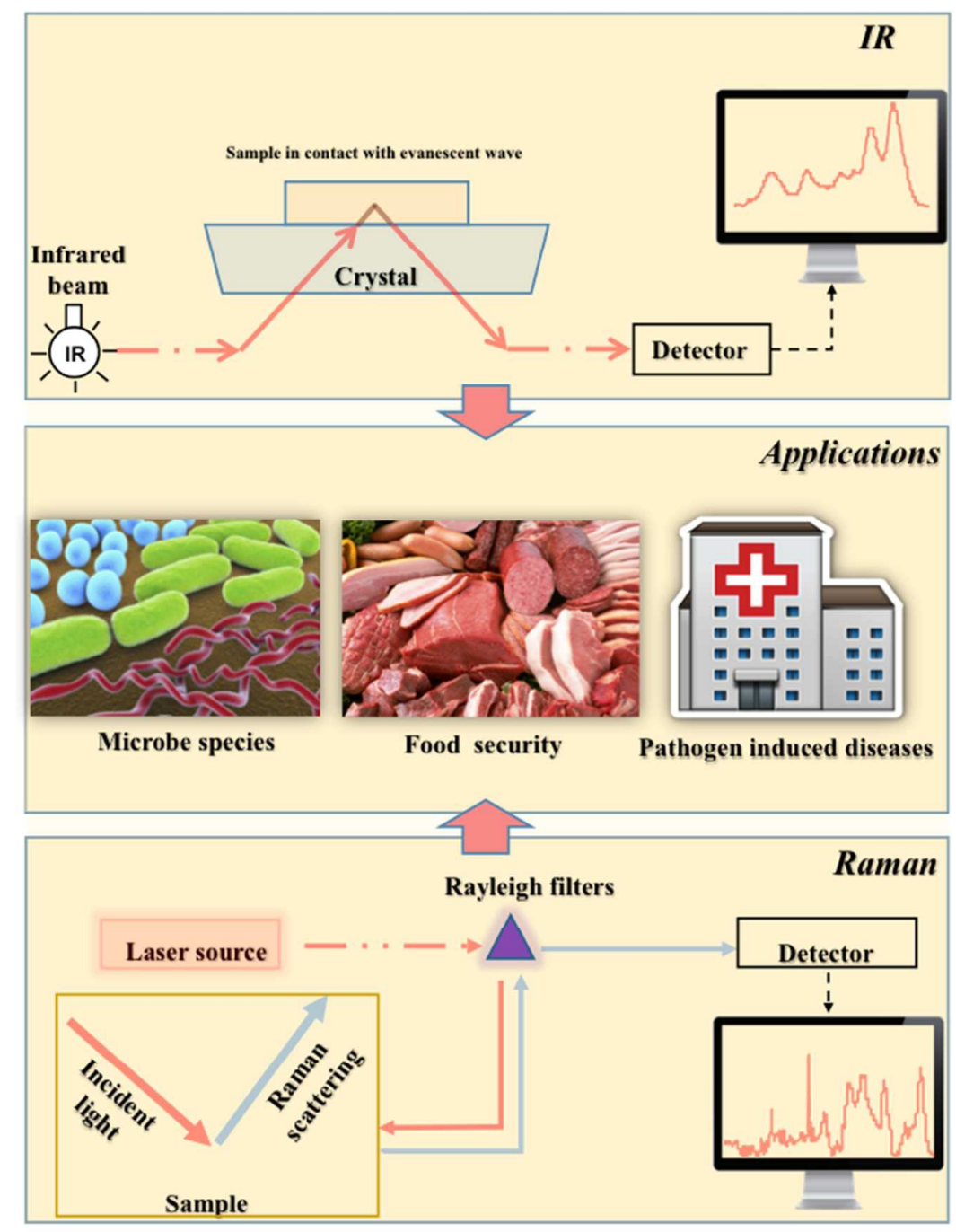

Figure 1. The principle of the biospectroscopic fingerprinting in identifying microbial species, examining food security and diagnosing pathogen-induced diseases. IR spectroscopy is capable of measuring the electric dipole state of chemical bonds in cellular molecules; Raman spectroscopy is a complementary tool exploiting the inelastic scattering of the targeted biological samples even under a hydrated environment. 
When biomolecules contain chemical bonds with an electric dipole moment, these vibrations are detectable and measurable by IR spectroscopy ${ }^{69}$. Categorized according to wavelengths (i.e., near-IR, mid-IR or far-IR), mid-IR (MIR) spectroscopy (4000-400 $\mathrm{cm}^{-1}$ in wavenumbers) is the most applied in biospectroscopy because it not only includes overtones but also contains fundamental vibrational transitions, providing inherently stronger signal intensities in terms of the increased absorption cross-section ${ }^{70}$. In 1991, FTIR spectroscopy was innovatively introduced as a sensitive and rapid screening tool for characterization, classification and identification of microorganisms ${ }^{71}$. Since then, FTIR spectroscopy has been extensively used in microbial research ${ }^{72-75}$. Among FTIR spectroscopic techniques, the most frequently applied IR spectroscopic techniques are transmission, transflection or attenuated total reflection (ATR) ${ }^{72}$. ATR-FTIR spectroscopy (Figure 1), for instance, which employs an internal reflection element with a high refractive index (e.g., diamond, germanium or zinc selenide), directs the IR beam for the total internal reflection and produces an evanescent wave that penetrates beyond the element by $1 \mu \mathrm{m}$ to $2 \mu \mathrm{m}$. It is used to interrogate biological samples allowing absorption of IR light and subsequently production of absorbance spectra ${ }^{69}$, 72 . This process can reveal biochemical information regarding cellular changes or alterations of samples. However, there is a significant limitation within FTIR in that water from instrumentation or samples may induce reduction of IR light transmission ${ }^{69,72}$. Hence, it is crucial to purge the instrumentation with dry air or nitrogen, as well as desiccants to remove any water vapour before spectral acquisition ${ }^{72}$. FTIR is a valuable metabolic fingerprinting tool owing to its abilities to characterize cellular composition ${ }^{72-78}$. In the mid-IR spectroscopy, the biochemical fingerprint region is from $1800-900 \mathrm{~cm}^{-1}$, and representative peaks include: lipids $\left(\sim 1750 \mathrm{~cm}^{-1}\right)$, Amide I $\left(\sim 1650 \mathrm{~cm}^{-1}\right)$, Amide II $\left(\sim 1550 \mathrm{~cm}^{-1}\right)$, Amide III $\left(\sim 1260 \mathrm{~cm}^{-1}\right)$, carbohydrates $\left(\sim 1155 \mathrm{~cm}^{-1}\right)$, asymmetric phosphate stretching vibrations $\left(v_{\mathrm{as}}\right.$ $\left.\mathrm{PO}_{2}^{-}, \sim 1225 \mathrm{~cm}^{-1}\right)$, symmetric phosphate stretching vibrations $\left(v_{\mathrm{s}} \mathrm{PO}_{2}^{-}, \sim 1080 \mathrm{~cm}^{-1}\right)$, glycogen $\left(\sim 1030 \mathrm{~cm}^{-1}\right)$, protein phosphorylation $\left(\sim 970 \mathrm{~cm}^{-1}\right)^{69,72,77,79,80}$. These peaks can be derived as biomarkers for characterization of microbial cell types (even at subspecies level) and diagnosis of microbe-induced diseases ${ }^{72-78}$. Metabolomics is a critical field that biospectroscopy could complement in order to investigate microbial metabolism.

Raman spectroscopy, a complementary biospectroscopic technique to FTIR, can generate information regarding chemical bonds even under a hydrated environment ${ }^{81-85}$. The monochromatic light in the near-IR, visible or UV range is used in Raman spectroscopy (Figure 1) to exploit the inelastic scattering or Raman effect. In this process, the excitation of photons to virtual energy states and the resultant loss (Stokes) or gain (anti-Stokes) of energy occurs because of the interaction of light with vibrational modes associated with chemical bonds within the sample ${ }^{80,86}$. This shift in energy is indicative of discrete vibrational modes of polarizable molecules, and thus a qualitative measurement of the biochemical composition can be obtained ${ }^{80,86}$. However, the inelastic scattering does not occur efficiently, the incidence is $<1 \%$ of the total photons absorbed by the molecules. Thus, backward light is then applied filtering off other interference, but the Raman scattering can reach the detector. Typically, the informative region of wavenumbers for biological samples is located within 
$400-2000 \mathrm{~cm}^{-1}$ and 2700-3500 $\mathrm{cm}^{-1}$, including proteins (1500-1700 $\left.\mathrm{cm}^{-1}\right)$, carbohydrates (470-1200 $\mathrm{cm}^{-1}$ ), phosphate groups of DNA (980, 1080 and $\left.1240 \mathrm{~cm}^{-1}\right)$ and higher-frequency bond vibrations of $\mathrm{CH}, \mathrm{NH}$ and $\mathrm{OH}$ stretching in lipids and proteins ${ }^{80,87}$. Applications of Raman spectroscopy in microbiology include bacterial discrimination, isolation, and identification $^{88-90}$.

\subsection{Applications of biospectroscopy in microbial research}

Compared to the conventional tools employed for identifying and characterizing the microbiome, biospectroscopy requires minimal sample amount and preparation, and is nondestructive and relatively high throughput ${ }^{69,72,80}$. Specifically, the minimal sample volume for ATR-FTIR and Raman spectroscopy is $3 \mu \mathrm{L}$ and $1 \mu \mathrm{L}$ respectively, much lower than those required in PCR, high-throughput sequencing, and Omics which require high quality and amounts of DNA template extracted from several millilitres or grams of environmental samples. Additionally, biospectroscopy does not require extra labelling, primer design, and enzymatic reaction, significantly reducing the cost and time in diagnosing. More importantly, the non-destructive features of biospectroscopy allow its application in vivo and in situ. Some successful microbial applications of biospectroscopy (Figure 1) include characterization of hospital isolates and rapid quantitative detection of the microbial spoilage of food products ${ }^{71}$, $77,79,91,92$. There is no doubt that biospectroscopy is a robust tool for distinguishing bacterial responses to environmental exposures due to its particular attributes of being non-destructive, non-intrusive, high throughput and label-free ${ }^{69,72}$. When coupled with conventional microscopy, biospectroscopy can be used to reproduce cell architecture from both the visual and biochemical perspective by the passing of spectral data through a variety of computational algorithms and capture of pictures simultaneously ${ }^{69}, 72$. It allows visualized monitoring and spectral interrogation undertaken in-situ in real-time, which is very helpful towards understanding the actual interactions between microbes and physical environment ${ }^{66}$, $69,72,77,80,93,94$. In the history of microbiological research, the microbiome is a particular hotspot in microbial ecology, challenging to all approaches to investigate it but bringing possibilities for biospectroscopy to be applied. As a very complicated bio-matrix, microbiomes contain various compositions contributing to the overall spectra, including extracellular polymeric substances (EPS), cell membrane, and the cytoplasm. The characteristic spectral peaks, e.g., biological macromolecules, may assess the existence and composition of biofilms by summarising the wavenumbers of detected peaks. Most EPS induced biomarkers, for instance, fall in the range of $1700-100 \mathrm{~cm}^{-1}$ in Raman spectroscopy ${ }^{95}$. Also, the comparison between the microbial biofilms and planktonic communities could reveal relevant biochemical information ${ }^{96}$. Specifically, Bosch et al. found FTIR spectra of biofilms demonstrated higher intensity in the absorption bands associated with polysaccharides $\left(1200-900 \mathrm{~cm}^{-1}\right.$ region) and vibrational modes of carboxylate groups $\left(1627,1405\right.$, and $\left.1373 \mathrm{~cm}^{-1}\right)$ than those of the planktonic ${ }^{74}$, showing evidence of dramatic difference of microbial living style within such communities. 


\section{Fingerprint microbiome via biospectroscopy}

\subsection{State of art}

Owing to the non-destructive and high-throughput possibilities, biospectroscopy has many advantages in diagnosing antibiotic resistance within a microbiome over other approaches, either function- or molecular-based ones. It allows fast and low-cost screening for an enormous number of samples and also provides a chance for further analysis of relevant mechanisms. Additionally, biospectroscopy is capable of monitoring real-time population dynamics and subsequently providing information of genotypic changes. However, until now, few biospectroscopy-based studies have focused on microbial antibiotic resistance, and all of the published studies ${ }^{97-99}$ investigate pure cultures. Lack of insight into microbiome structures in situ highlights the urgent need for novel approaches. The primary challenges currently include the lack of a reliable database, routine protocols, and reproducible computational analysis, which determine the feasibility of biospectroscopy distinguishing biomarkers representing antibiotic resistance from the numerous fingerprints in environmental backgrounds.

Herein, we propose a state-of-the-art biospectroscopic application in assessing microbial antibiotic resistance within a microbiome. Within a microbiota of interest, there is no doubt biospectroscopy has the ability to allow the quick identification of microbial species within a well-built dataset ${ }^{97}$. Furthermore, biospectroscopy can diagnose microbe-induced diseases in clinical settings contributing to the advantages of early detection and stratification of at-risk patients to initiate timely and appropriate treatment ${ }^{100-103}$. Raman spectroscopy has successfully identified sepsis in blood plasma from 70 patients with a satisfactory sensitivity of 1.0 and specificity of $0.82^{101}$. The feasibility of biospectroscopic investigation into microbial alterations induced by exposures has also been evaluated. Riding et al. applied IR spectroscopy to fingerprint microbes following exposure to carbon nanoparticles, and revealed concentration- and size-dependent changes in cellular components ${ }^{104}$. Another study ${ }^{105}$ confirmed the ability of IR spectroscopy to characterize changes induced by carbon nanoparticles via investigating their effects in both Gram positive and negative bacteria. Some discriminant biochemical markers, i.e., Amide II and carbohydrate, were picked out to verify the distinct alterations in bacteria with respective cell wall structures. These studies prove that biospectroscopy is not only able to distinguish microbial response to different kinds of exposures, but also specify variances resulting from bacterial structures, demonstrating its potential to diagnose antibiotic resistance with reliable biomarkers.

To investigate in-situ the construction and composition of microbiota in real-time, a non-destructive and non-intrusive method is required to delineate differentiation. Biospectroscopy is such an optical sensor, an in-situ non-labelling complementary to other molecular-based techniques, by directly and remotely measuring molecular vibration spectra in living cells ${ }^{106}$ and biofilms ${ }^{107}$. Given this, we propose a new system for characterizing antibiotic resistance within whole microbiomes via a rapid and high-throughput manner (Figure 2). Firstly, by well-trained databases, the abundance of ARGs or microbes with 
ARGs in microbiotas can be quantified by evaluating the alteration ratio of biomarkers from multivariate statistical analysis. Furthermore, the dynamics of ARGs in microbiotas might be assessed in real-time via the interrogation of changes in biomarker change. Achieved in-situ and real-time investigation of antibiotic resistance, the ultimate goal of this approach is to monitor and diagnose both the presence and change of ARGs in unknown environmental or human samples of interest, differentiating alterations of discriminating biomarkers in-situ and real-time without referencing trained datasets.

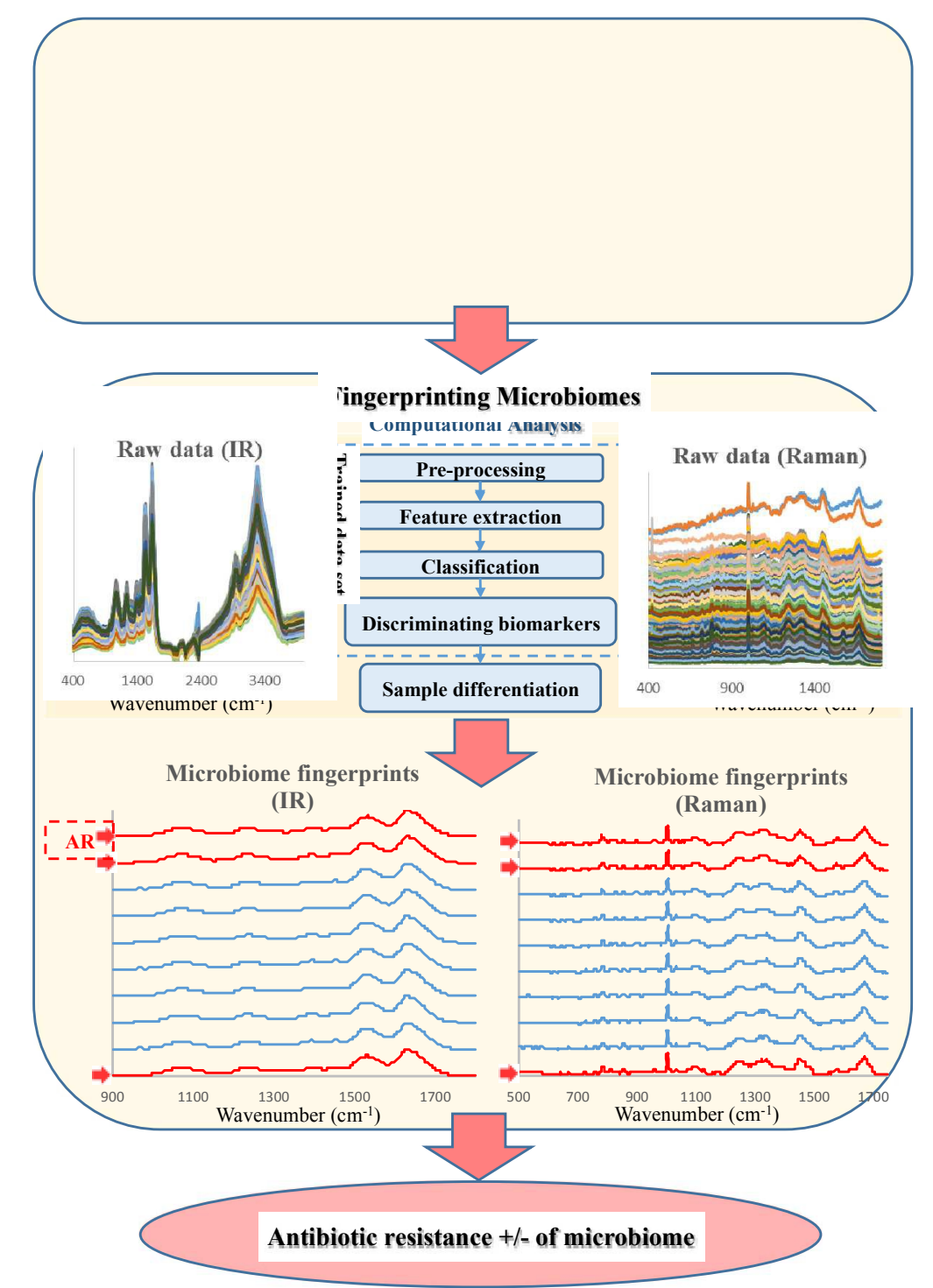

Figure 2. Schematic diagram of biospectroscopy fingerprinting microbiome for antibiotic resistance. Portal bio-spectroscopic devices achieve in situ and real-time interrogation of spectra from the samples of interest, e.g., human microbiome and livestock farm microbiome. The fingerprints are further processed via computational analysis (pre-processing, feature extraction, classification, discrimination, and differentiation) to distinguish the spectral biomarkers of antibiotic resistance. Comparing to well-trained databases with both positive 
and negative controls, the biomarker alterations can examine the antibiotic resistance capability of the targeted microbiome or even quantify the abundance of antibiotic resistance genes.

\subsection{Proof of concept}

Our pre-validating results indicate biospectroscopy can determine the abundance of bacteria with ARG in microbiome (Figure 3A), despite disparate bacterial types and community composition (Gram-positive or Gram-negative; Figure 3B). From the well-trained dataset and discriminating biomarkers (Figure 3C), the fingerprints of unknown microbiomes are allocated and assigned with their ARGs abundance after encoding. Furthermore, both the static and dynamic microbial matrices can be quantified by biospectroscopy due to inherently non-destructive and non-intrusive attribute (Figure 3D). Here, biospectroscopy is validated as a high throughput screening method for characterization of microbial composition and ARGs abundance in complex matrices.

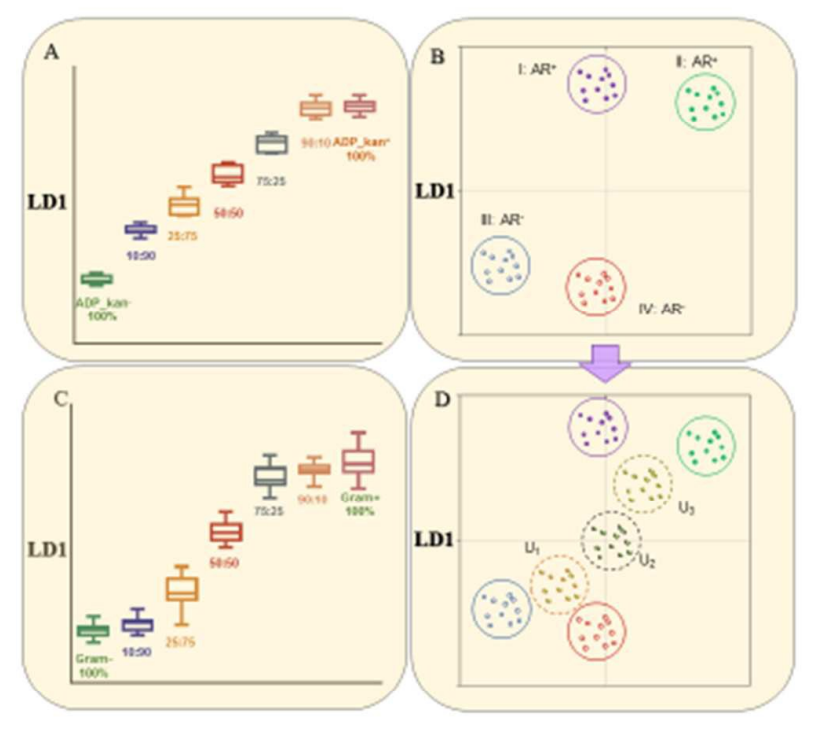

Figure 3. Pre-validation proves the feasibility of interrogating the abundance of ARGs and ratio of Gram-positive to Gram-negative bacteria in microbiomes. ARGs identification in microbiome by biospectroscopic fingerprints via a Bruker TENSOR 27 FTIR spectrometer (Bruker Optics Ltd., UK) equipped with a Helios ATR attachment containing a diamond internal reflection element (IRE). Instrument parameters were set at 32 scans, $16 \mathrm{~cm}^{-1}$ 
resolution. A total of 30 spectra were acquired for each treatment (3 replicates) through the ATR magnification-limited viewfinder camera. (A) Prediction of ARGs abundance in artificial microbial communities containing different compositions of two Acinetobacter baylyi mutants, ADP_kan ${ }^{-}$and ADP_kan ${ }^{+}$, which are genetically identical apart from the kanamycin resistance gene located on the chromosome of ADP_kan ${ }^{+}$. Under kanamycin antibiotic pressure, i.e., treated with final concentration of kanamycin, the discriminant biomarkers were $\left(\sim 980 \mathrm{~cm}^{-1}\right)$, Oligosaccharide $\mathrm{C}-\mathrm{OH}$ stretching band $\left(\sim 1138 \mathrm{~cm}^{-1}\right)$, Deoxyribose $\left(\sim 1188 \mathrm{~cm}^{-1}\right)$, Amide III $\left(\sim 1242 \mathrm{~cm}^{-1}\right)$, In-plane $\mathrm{CH}$ bending vibration from the phenyl rings $\left(\sim 1500 \mathrm{~cm}^{-1}\right), \mathrm{C}=\mathrm{O}$ stretching, lipids $\left(\sim 1740 \mathrm{~cm}^{-1}\right)$. The LDA distance is positively correlated with the ratio of $\mathrm{ADP} \mathrm{kan}^{-} / \mathrm{ADP} \mathrm{kan}^{+}$and the linear regression, therefore, can be used for ARG abundance calculation. (B) Prediction of microbial community composition artificial microbial communities containing Gram-positive $\left(\right.$ Mycobacterium vanbaalenii, $\mathrm{Gram}^{+\mathrm{ve}}$ ) and Gram-negative (Acinetobacter baylyi ADP_kan ${ }^{+}$, $\mathrm{Gram}^{-\mathrm{ve}}$ ) bacteria. The positive correlation between LDA distance and the ratio of $\mathrm{Gram}^{+\mathrm{ve}}$ / $\mathrm{Gram}^{\text {-ve }}$ helps in determining the abundance of each strain. (C) Dataset from LDA differentiation of four reference bacterial strains $\left(\mathrm{AGR}^{+}\right.$: bacteria I and bacteria II with $\mathrm{ARG}$; AGR $^{-}$: bacteria III and bacteria IV with no ARG). The dataset is well trained for separating $\mathrm{ARG}^{+}$and $\mathrm{ARG}^{-}$bacteria. (D) LDA differentiation of unknown microbiome $\left(\mathrm{U}_{1}, \mathrm{U}_{2}\right.$, and $\left.\mathrm{U}_{3}\right)$ compared to training dataset to determine the abundance of ARG. Based on the values generated from LDA analysis, their biochemical distances can be calculated. These results validate bio-spectroscopy is capable of characterizing and quantifying ARGs of microbes via their phenotypes in both genetically identical and differential microbial communities. Also, it can be used to determine antibiotic resistance of unknown samples by calculating their biochemical distances.

\section{Challenges and solutions}

\subsection{Dataset}

As mentioned above, a well-trained dataset is the key for biospectroscopic fingerprinting microbiome and also the first fundamental problem challenge concerned which can eliminate confounding factors, i.e., criteria may contribute a disruption to the core purpose of the study. To achieve this goal, the database of relevant molecular fingerprint and their assignments (such as nucleic acids, proteins, polysaccharides, carbohydrate, and lipids) have to be wellcharacterised since the bio-spectroscopic classifications are based on calculating alterations of interaction involved cellular compositions. This work may significantly improve biospectroscopy from both quantity and quality criteria ${ }^{108}$. Detailed information of the most widely used peak frequencies and their assignments refers to the reviews of IR spectroscopy ${ }^{108}$, Raman spectroscopy ${ }^{52,87}$, and ratios $\left(\mathrm{X} \mathrm{cm}^{-1} / \mathrm{Y} \mathrm{cm}^{-1}\right)^{109}$. These peaks with remarkable alterations are determined as discriminating biomarkers for diagnosis of changes resulted by specific exposures in many studies ${ }^{69}, 87,104,105,108,110$. However, no biospectroscopy-relevant study has yet been found associated with biomarkers for antibiotic 
resistance of microbiomes.

\subsection{Growth phase and environmental variants}

Another major concern for the overall study (i.e., confounding factors) is bacterial communities are incredibly complicated in terms of their composition, species, dynamics of population, growth phase and nutrient depletion impacts ${ }^{111-114}$. Growth phase effect for instance, which may result in remarkable discrepancies within cell growth circle regarding physical features and biochemical compositions. Ede et al. ${ }^{115}$ reported all the examined species showed significant spectral differences through their growth phases in a study of assessing cell population growth via ATR-FTIR spectroscopy. They found $B$. stearothermophilus had a major change associated with lipid content and reached peak position during the log phase; for the halophiles H. salinarium and H.morrhuae, the most significant alteration was the concentration of sulphate ion. Mainly, at the mid-log phase, $A$. aceti cells showed increasing polysaccharide content along with and also a maximum change of lipid content was noticed during the log phase. These growth phase induced changes may lead to distinct responses of microbes to exposures ${ }^{115-118}$.
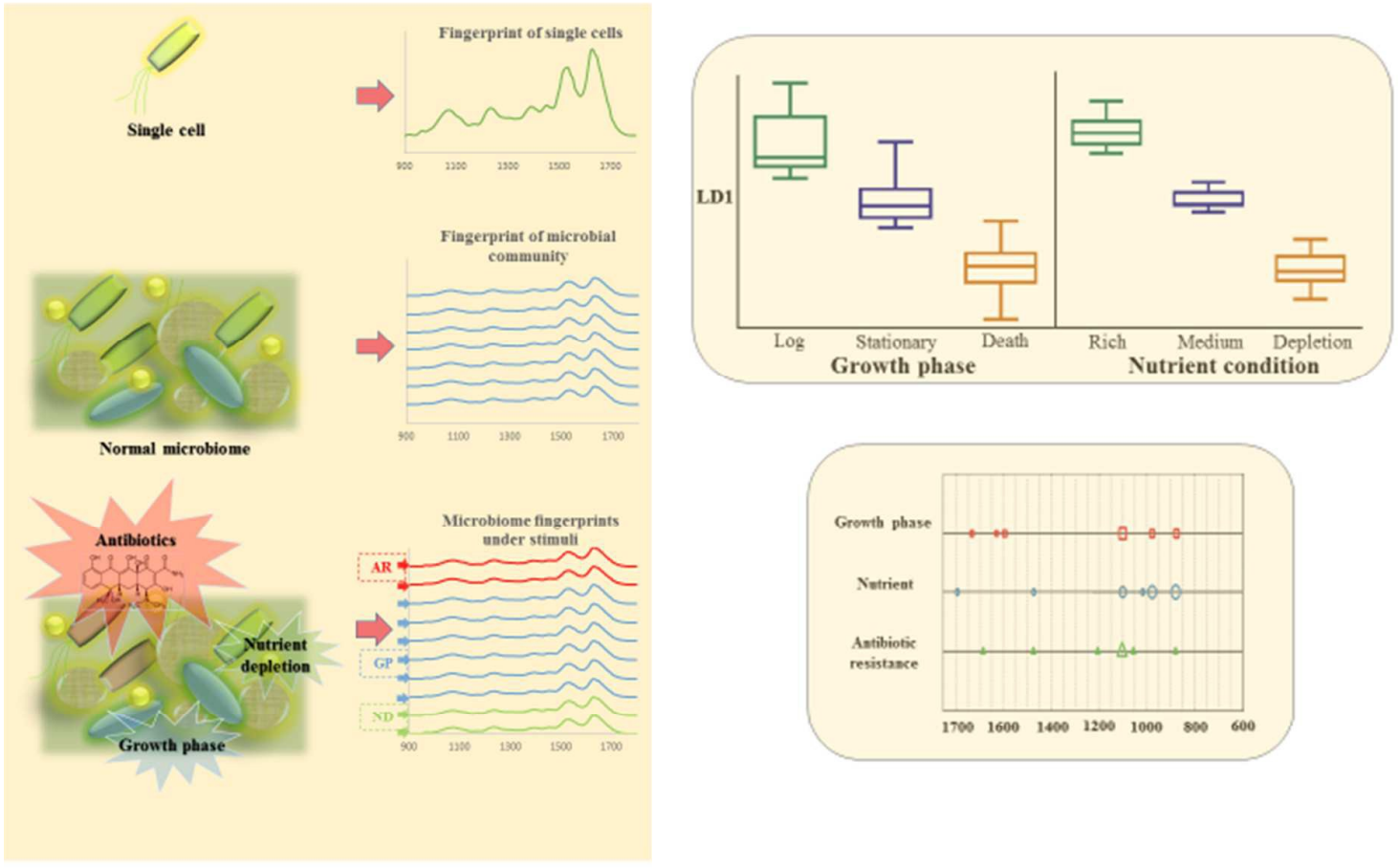

Figure 4. Pre-validation of solutions for proposed challenges of growth phase and nutrients. The well-trained dataset eliminating other environmental interference is built-up in several steps: 1) Reference dataset acquisition from individual single cell of different species representing their biospectral attributes; 2) Biospectra acquisition from the targeted microbiome; 3) Biospectra acquisition from the targeted microbiome postexposure to 
antibiotics to recognize and separate the discriminating spectral alterations via multivariate analysis; and, 4) The identical and consistent spectral alterations representing antibiotic resistance markers are clustered for interrogating the targeted microbiome.

A substantial alteration gradient of bio-spectra is noticed along with growth phase and nutrient conditions, respectively. However, discrimination of antibiotic resistance biomarkers is independent of growth phase and nutrient conditions (Figure 4). The biomarkers of antibiotic resistance, i.e., phenylalanine (protein assignment) $\left(\sim 1004 \mathrm{~cm}^{-1}\right.$ and $\left.\sim 1376 \mathrm{~cm}^{-1}\right)$, hydroxyapatite, carotenoid, cholesterol $\left(\sim 957 \mathrm{~cm}^{-1}\right)$, uracil-based ring breathing mode $(\sim 780$ $\left.\mathrm{cm}^{-1}\right)$, carbohydrates $\left(\sim 1105 \mathrm{~cm}^{-1}\right)$, phenylalanine, hydroxyproline $\left(\sim 1586 \mathrm{~cm}^{-1}\right)$, are significantly discriminated from those of growth phases, phenylalanine or bound \& free NADH $\left(\sim 1000 \mathrm{~cm}^{-1}\right)$, phosphatidylinositol $\left(\sim 776 \mathrm{~cm}^{-1}\right), \mathrm{C}-\mathrm{C}-\mathrm{N}^{+}$symmetric stretching (lipids) or C-O-C ring (carbohydrate) $\left(\sim 877 \mathrm{~cm}^{-1}\right.$ and $\left.\sim 1495 \mathrm{~cm}^{-1}\right)$, Amide I $\left(\sim 1634 \mathrm{~cm}^{-1}\right.$ and $\sim 1530$ $\left.\mathrm{cm}^{-1}\right)$; and nutrients, uracil-based ring breathing mode $\left(\sim 780 \mathrm{~cm}^{-1}\right), \mathrm{C}-\mathrm{C}-\mathrm{N}^{+}$symmetric stretching (lipids) or C-O-C ring (carbohydrate) $\left(\sim 877 \mathrm{~cm}^{-1}\right)$, phenylalanine or bound \& free NADH $\left(\sim 1000 \mathrm{~cm}^{-1}\right)$, proline, hydroxyproline or glycogen and lactic acid $\left(\sim 918 \mathrm{~cm}^{-1}, \sim 1695\right.$ $\mathrm{cm}^{-1}$ and $\sim 1375 \mathrm{~cm}^{-1}$ ) implying biospectroscopic is able to identify antibiotic resistance within a microbiome regardless of impacts from growth phase and nutrient condition. Therefore, these discriminating biomarkers associated with antibiotic resistance reveal the potential feasibility for in-situ diagnosis of real samples despite environmental variants. It is worth mentioning that discrimination of antibiotic resistance biomarkers might be also affected by the complicated effects of antibiotics on both targeted microbiome and their matrix environment, particularly in case of interrogating biofilm on mammalian tissues. The production of tissue mucus and other components or the interference signals from mammalian tissues themselves can bring challenges in distinguishing the proper biospectral biomarkers. Although no previous report has answered this question yet, some potential solutions eliminating background noise include separating microbiome from via optical tweezers ${ }^{119}$ or flow cytometry ${ }^{120}$.

\subsection{Computational analysis}

It needs to be highlighted the most vital component associated with biospectroscopic determination for antibiotic resistance of microbiome is to find discriminating biomarkers, i.e., the most absolute and representative peaks derived from acquired spectra, allowing subsequently high throughput screening for determination of antibiotic resistance. Although some alterations of biomarkers can be visualized by eyes, the questions always emerge regarding the existence of noticed difference and the reliability of subjective assessing by eye. Hence, computational analysis is applied to exam the data due to the acquired spectrums holding an enormous number of features.

The pre-processing is the first step of computational analysis which aims to reduce effects resulted from spectral acquisition and subsequently enhance the robustness and accuracy as well as making all the raw data comparable ${ }^{72}$. Categories of pre-processing 
include de-noising, spectral correction, normalization and combinations of these processes. For a raw dataset of Raman, a noise-reduction smoothing step is commonly applied to increase the SNR (signal-to-noise ratio) and highlight spectral features associated with biochemical information ${ }^{69}$. PCA is also used to achieve the purpose of de-nosing because the most valuable features of spectra can be represented by several significant PCs while the rest PCs containing a majority of noise can be ignored. Furthermore, there is a huge challenge in the procession of raw data, i.e., sloped or oscillatory baselines associated with resonant Mie scattering in IR spectroscopy or fluorescence in Raman spectroscopy ${ }^{72}$. To solve this issue, rubber band baseline correction is applied for IR which produced a convex polygonal line to correct the bottom edges of the spectra; and polynomial fit for Raman, which generates a polynomial baseline to adjust the spectral minima ${ }^{121}$. Also, the most vital part of preprocessing is the normalization, which eliminates the confounding factors, thickness or concentration, for instance, making acquired spectra comparable within intra-class and interclass. For biological samples, Amide I $(\sim 1650 \mathrm{~cm}-1) / \mathrm{II}\left(\sim 1550 \mathrm{~cm}^{-1}\right)$ is usually applied after baseline correction for IR data; and vector normalization (Euclidean or L2-norm) is used for Raman data ${ }^{72,121}$.

Moreover, the multivariate statistical analysis is an ideal tool for spectral analysis. In 2010, Martin et al. proposed two objectives for spectral assessing biological materials using multivariate statistical analysis: (i) to determine similarities and differences between classes (categories within the dataset, e.g., cell types); and (ii) to identify the spectral bands that mostly relate to these similarities and differences. So as to meet the objectives, classification is introduced as one of the core components in multivariate analysis, which typically relies on clustering techniques, such as hierarchical cluster analysis, k-means clustering, fuzzy Cmeans clustering and PCA. Furthermore, PCA-LDA is an ideal classification tool to investigate intra-class or interclass variation. As compared to PCA alone, the additional linear discriminant analysis derives vectors from the principal components (PCs) and minimizes the within-category differences (mostly be associated with typical heterogeneity in any biological sample) while maximizing between-category discriminating characteristics (i.e., those most likely to be induced by treatments or other exogenous contributions) $)^{69,72,80}$.

\section{Future prospects}

The introduction of biospectroscopic screening allows rapid in-situ diagnosis of antibiotic resistance in microbiomes as well as real-time detection of population dynamics and determination of genotype flexibility (e.g., HGT process and microbial response to antibiotic pressure) via monitoring phenotype differentiation, which can significantly improve the understanding of antibiotic resistance in the clinical and physical environment. Furthermore, a combination of cultivation-based approaches coupled with fast screening may solve the inherent limitation of cultivation that microbial functioning in natural environments is difficult to study by cultivation solely due to uncultivable microbes and their complicated community constructions $^{93,122}$. Also, with the non-destructive character of bio-spectroscopic fast screening reducing the amount of interrogating targets, many other techniques can be attached for further investigation, e.g., single cell sorting ${ }^{54,57}$, -omics $^{40}$, etc. One good 
example can be found in Huang's work describing novel marine strain identification via Raman spectroscopy coupled with single-cell genomics ${ }^{123}$. Raman spectra are also reported in morphology-specific genomic analysis of human tissues combined with microdissection sequencing $^{124}$ or characterizing metabolic alterations in mouse liver coupled with metabolomics and transcriptomics ${ }^{125}$. These combinations may significantly enhance the study of the relevant mechanisms providing an opportunity for direct determination of precisely functional genes and proteins. Ultimately, genotype and phenotype can be linked together from the population, single cell, and molecular perspectives to determine the antibiotic resistance in the microbiota of interest and consequently help us better understand the actual interactions among humans, microbes, and the physical environment. 


\section{References}

1. M. Breitbart and F. Rohwer, Trends Microbiol., 2005, 13, 278-284.

2. J. A. Fuhrman, Nature, 2009, 459, 193-199.

3. N. Fierer, M. Hamady, C. L. Lauber and R. Knight, Proc. Natl. Acad. Sci. U. S. A., 2008, 105, 17994-17999.

4. M. Candela, E. Biagi, S. Maccaferri, S. Turroni and P. Brigidi, Trends Microbiol., 2012, 20, 385-391.

5. D. A. Hill, C. Hoffmann, M. C. Abt, Y. Du, D. Kobuley, T. J. Kirn, F. D. Bushman and D. Artis, Mucosal Immunol., 2010, 3, 148-158.

6. M. T. Bailey, S. E. Dowd, J. D. Galley, A. R. Hufnagle, R. G. Allen and M. Lyte, Brain. Behav. Immun., 2011, 25, 397-407.

7. C. Jernberg, S. Lofmark, C. Edlund and J. K. Jansson, Microbiology, 2010, 156, 32163223.

8. K. Lu, R. P. Abo, K. A. Schlieper, M. E. Graffam, S. Levine, J. S. Wishnok, J. A. Swenberg, S. R. Tannenbaum and J. G. Fox, Environ. Health Perspect., 2014, 122, 284-291.

9. E. A. Mutlu, P. M. Gillevet, H. Rangwala, M. Sikaroodi, A. Naqvi, P. A. Engen, M. Kwasny, C. K. Lau and A. Keshavarzian, Am J Physiol Gastrointest Liver Physiol, 2012, 302, G966-978.

10. N. Takahashi, 2005.

11. A. Gonzalez, J. C. Clemente, A. Shade, J. L. Metcalf, S. Song, B. Prithiviraj, B. E. Palmer and R. Knight, EMBO Rep, 2011, 12, 775-784.

12. A. Koluman and A. Dikici, Crit. Rev. Microbiol., 2013, 39, 57-69.

13. J. W. Harrison and T. A. Svec, Quintessence int., 1998, 29, 223-229.

14. X. Ji, Q. Shen, F. Liu, J. Ma, G. Xu, Y. Wang and M. Wu, J. Hazard. Mater., 2012, 235, 178-185.

15. J. C. Chee-Sanford, R. I. Aminov, I. J. Krapac, N. Garrigues-Jeanjean and R. I. Mackie, Appl. Environ. Microbiol., 2001, 67, 1494-1502.

16. L. Cantas, S. Q. Shah, L. M. Cavaco, C. M. Manaia, F. Walsh, M. Popowska, H. Garelick, H. Burgmann and H. Sorum, Front. Microbiol., 2013, 4, 96.

17. M. Tandukar, S. Oh, U. Tezel, K. T. Konstantinidis and S. G. Pavlostathis, Environ. Sci. Technol., 2013, 47, 9730-9738.

18. J. L. Martinez and F. Baquero, Ups. J. Med. Sci., 2014, 119, 68-77.

19. J. Conly, CMAJ, 2002, 167, 885-891.

20. M. Sundqvist, Ups. J. Med. Sci., 2014, 119, 142-148.

21. C. S. Smillie, M. B. Smith, J. Friedman, O. X. Cordero, L. A. David and E. J. Alm, Nature, 2011, 480, 241-244.

22. G. D. Wright, Chem. Biol., 2000, 7, R127-R132.

23. T. Häusler, Viruses vs. superbugs: a solution to the antibiotics crisis?, Palgrave Macmillan, 2006.

24. P. Southern and P. Berg, J. Mol. Appl. Genet., 1981, 1, 327-341.

25. K. J. Forsberg, A. Reyes, B. Wang, E. M. Selleck, M. O. Sommer and G. Dantas, Science, 2012, 337, 1107-1111.

26. J. L. Martínez, Science, 2008, 321, 365-367.

27. A. A. Salyers, A. Gupta and Y. Wang, Trends Microbiol., 2004, 12, 412-416.

28. T. Schwartz, W. Kohnen, B. Jansen and U. Obst, FEMS Microbiol. Ecol., 2003, 43, 325-335.

29. C. Martin, J. Timm, J. Rauzier, R. Gomez-Lus, J. Davies and B. Gicquel, Nature, 1990, 345, 739-743. 
30. L. Rizzo, C. Manaia, C. Merlin, T. Schwartz, C. Dagot, M. Ploy, I. Michael and D. Fatta-Kassinos, Sci. Total Environ., 2013, 447, 345-360.

31. D. Nichols, FEMS Microbiol. Ecol., 2007, 60, 351-357.

32. M. R. Rondon, P. R. August, A. D. Bettermann, S. F. Brady, T. H. Grossman, M. R. Liles, K. A. Loiacono, B. A. Lynch, I. A. MacNeil and C. Minor, Appl. Environ. Microbiol., 2000, 66, 2541-2547.

33. N. A. Séveno, D. Kallifidas, K. Smalla, J. D. van Elsas, J.-M. Collard, A. D. Karagouni and E. M. Wellington, Rev. Med. Microbiol., 2002, 13, 15-27.

34. K. Bartscht, H. Cypionka and J. Overmann, FEMS Microbiol. Ecol., 1999, 28, 249259.

35. J. Clardy and C. Walsh, Nature, 2004, 432, 829-837.

36. W. R. Streit and R. A. Schmitz, Curr. Opin. Microbiol., 2004, 7, 492-498.

37. S. Radajewski, P. Ineson, N. R. Parekh and J. C. Murrell, Nature, 2000, 403, 646-649.

38. D. Zhang, J. P. Berry, D. Zhu, Y. Wang, Y. Chen, B. Jiang, S. Huang, H. Langford, G. Li and P. A. Davison, The ISME journal, 2015, 9, 603-614.

39. C. S. Riesenfeld, R. M. Goodman and J. Handelsman, Environ. Microbiol., 2004, 6, 981-989.

40. M. Tyers and M. Mann, Nature, 2003, 422, 193-197.

41. M. O. A. Sommer, G. Dantas and G. M. Church, Science, 2009, 325, 1128-1131.

42. K. J. Forsberg, 2015.

43. J. Handelsman, Microbiol. Mol. Biol. Rev., 2004, 68, 669-685.

44. M. Diaz-Torres, R. McNab, D. Spratt, A. Villedieu, N. Hunt, M. Wilson and P. Mullany, Antimicrob. Agents Chemother., 2003, 47, 1430-1432.

45. H. C. Flemming and J. Wingender, Nat. Rev. Microbiol., 2010, 8, 623-633.

46. E. Karunakaran, J. Mukherjee, B. Ramalingam and C. Biggs, Appl Microbiol Biotechnol, 2011, 90, 1869-1881.

47. X. N. Lu, D. R. Samuelson, B. A. Rasco and M. E. Konkel, J. Antimicrob. Chemother., 2012, 67, 1915-1926.

48. H. Y. N. Holman, R. Miles, Z. Hao, E. Wozei, L. M. Anderson and H. Yang, Anal. Chem., 2009, 81, 8564-8570.

49. P. S. Stewart, Int. J. Med. Microbiol., 2002, 292, 107-113.

50. D. Berry, E. Mader, T. K. Lee, D. Woebken, Y. Wang, D. Zhu, M. Palatinszky, A. Schintlmeister, M. C. Schmid and B. T. Hanson, Proc. Natl. Acad. Sci. U.S.A., 2015, 112, E194-E203.

51. W. E. Huang, M. J. Bailey, I. P. Thompson, A. S. Whiteley and A. J. Spiers, Microb. Ecol., 2007, 53, 414-425.

52. W. E. Huang, M. Q. Li, R. M. Jarvis, R. Goodacre and S. A. Banwart, Adv. Appl. Microbiol., Vol 70, 2010, 70, 153-186.

53. W. E. Huang, Y. Song and J. Xu, Microb. Biotechnol., 2015, 8, 15-16.

54. W. E. Huang, A. D. Ward and A. S. Whiteley, Environ. Microbiol. Rep., 2009, 1, 4449.

55. M. Li, D. G. Boardman, A. Ward and W. E. Huang, Methods Mol. Biol., 2014, 1096, 147-153.

56. M. Q. Li, J. Xu, M. Romero-Gonzalez, S. A. Banwart and W. E. Huang, Curr. Opin. Biotechnol., 2012, 23, 56-63.

57. Y. Song, H. Yin and W. E. Huang, Curr. Opin. Chem. Biol., 2016, 33, 1-8.

58. Y. Wang, Y. Chen, Q. Zhou, S. Huang, K. Ning, J. Xu, R. M. Kalin, S. Rolfe and W. E. Huang, PLoS One, 2012, 7, e47530.

59. Y. Wang, W. E. Huang, L. Cui and M. Wagner, Curr. Opin. Biotechnol., 2016, 41, 3442. 
60. P. Zhang, L. Ren, X. Zhang, Y. Shan, Y. Wang, Y. Ji, H. Yin, W. E. Huang, J. Xu and B. Ma, Anal. Chem., 2015, 87, 2282-2289.

61. M. Kaern, T. C. Elston, W. J. Blake and J. J. Collins, Nat Rev Genet, 2005, 6, 451464.

62. M. B. Elowitz, A. J. Levine, E. D. Siggia and P. S. Swain, Science, 2002, 297, $1183-$ 1186.

63. J. M. Raser and E. K. O'Shea, Science, 2004, 304, 1811-1814.

64. A. P. Feinberg and R. A. Irizarry, Proc. Natl. Acad. Sci. U.S.A., 2010, 107, 1757-1764.

65. J.-W. Veening, W. K. Smits and O. P. Kuipers, Annu. Rev. Microbiol., 2008, 62, 193210.

66. P. Heraud and M. J. Tobin, Stem Cell Research, 2009, 3, 12-14.

67. J. Heber, R. Sevenson and O. Boldman, Science, 1952, 116, 11.

68. K. Norris, J. Hyg. (Lond.), 1959, 57, 326-345.

69. F. L. Martin, J. G. Kelly, V. Llabjani, P. L. Martin-Hirsch, Patel, II, J. Trevisan, N. J. Fullwood and M. J. Walsh, Nat. Protoc., 2010, 5, 1748-1760.

70. J. G. Kelly, J. Trevisan, A. D. Scott, P. L. Carmichael, H. M. Pollock, P. L. MartinHirsch and F. L. Martin, J. Proteome Res., 2011, 10, 1437-1448.

71. D. Naumann, D. Helm and H. Labischinski, Nature, 1991, 351, 81-82.

72. M. J. Baker, J. Trevisan, P. Bassan, R. Bhargava, H. J. Butler, K. M. Dorling, P. R. Fielden, S. W. Fogarty, N. J. Fullwood, K. A. Heys, C. Hughes, P. Lasch, P. L. MartinHirsch, B. Obinaju, G. D. Sockalingum, J. Sule-Suso, R. J. Strong, M. J. Walsh, B. R. Wood, P. Gardner and F. L. Martin, Nat. Protoc., 2014, 9, 1771-1791.

73. J. Schmitt and H.-C. Flemming, Int. Biodeterior. Biodegradation, 1998, 41, 1-11.

74. A. Bosch, D. Serra, C. Prieto, J. Schmitt, D. Naumann and O. Yantorno, Appl. Microbiol. Biotechnol., 2006, 71, 736-747.

75. J. J. Ojeda, M. E. Romero-González, R. T. Bachmann, R. G. Edyvean and S. A. Banwart, Langmuir, 2008, 24, 4032-4040.

76. B. R. Wood, M. A. Quinn, B. Tait, M. Ashdown, T. Hislop, M. Romeo and D. McNaughton, Biospectroscopy, 1998, 4, 75-91.

77. W. B. Dunn and D. I. Ellis, TrAC Trends in Analytical Chemistry, 2005, 24, 285-294.

78. L. Mariey, J. Signolle, C. Amiel and J. Travert, Vib Spectrosc., 2001, 26, 151-159.

79. E. Lipiec, G. Birarda, J. Kowalska, J. Lekki, L. Vaccari, A. Wiecheć, B. Wood and W. Kwiatek, Radiat. Phys. Chem., 2013, 93, 135-141.

80. H. J. Butler, L. Ashton, B. Bird, G. Cinque, K. Curtis, J. Dorney, K. Esmonde-White, N. J. Fullwood, B. Gardner, P. L. Martin-Hirsch, M. J. Walsh, M. R. McAinsh, N. Stone and F. L. Martin, Nat. Protoc., 2016, 11, 664-687.

81. A. A. Ahmadzai, J. Trevisan, N. J. Fullwood, P. L. Carmichael, A. D. Scott and F. L. Martin, Mutagenesis, 2012, 27, 257-266.

82. S. Creton, M. J. Aardema, P. L. Carmichael, J. S. Harvey, F. L. Martin, R. F. Newbold, M. R. O’Donovan, K. Pant, A. Poth and A. Sakai, Mutagenesis, 2012, 27, 93-101.

83. K. Gajjar, J. Trevisan, G. Owens, P. J. Keating, N. J. Wood, H. F. Stringfellow, P. L. Martin-Hirsch and F. L. Martin, Analyst, 2013, 138, 3917-3926.

84. J. Trevisan, P. P. Angelov, I. I. Patel, G. M. Najand, K. T. Cheung, V. Llabjani, H. M. Pollock, S. W. Bruce, K. Pant and P. L. Carmichael, Analyst, 2010, 135, 3266-3272.

85. M. J. Walsh, S. W. Bruce, K. Pant, P. L. Carmichael, A. D. Scott and F. L. Martin, Toxicology, 2009, 258, 33-38.

86. K. Kneipp, H. Kneipp, I. Itzkan, R. R. Dasari and M. S. Feld, Chem. Rev., 1999, 99, 2957-2976.

87. Z. Movasaghi, S. Rehman and I. U. Rehman, Appl. Surf. Sci., 2007, 42, 493-541.

88. R. M. Jarvis and R. Goodacre, Anal. Chem., 2004, 76, 40-47. 
89. K. Maquelin, C. Kirschner, L.-P. Choo-Smith, N. van den Braak, H. P. Endtz, D. Naumann and G. Puppels, J. Microbiol. Methods, 2002, 51, 255-271.

90. S. Pahlow, S. Meisel, D. Cialla-May, K. Weber, P. Rösch and J. Popp, Adv. Drug Deliv. Rev., 2015, 89, 105-120.

91. R. Goodacre, E. M. Timmins, P. J. Rooney, J. J. Rowland and D. B. Kell, FEMS Microbiol. Lett., 1996, 140, 233-239.

92. D. I. Ellis, D. Broadhurst, D. B. Kell, J. J. Rowland and R. Goodacre, Appl. Environ. Microbiol., 2002, 68, 2822-2828.

93. W. E. Huang, R. I. Griffiths, I. P. Thompson, M. J. Bailey and A. S. Whiteley, Anal. Chem., 2004, 76, 4452-4458.

94. H. Li, F. L. Martin and D. Zhang, Anal. Chem., 2017, 89, 3909-3918.

95. T. Schwartz, C. Jungfer, S. Heißler, F. Friedrich, W. Faubel and U. Obst, Chemosphere, 2009, 77, 249-257.

96. E. Karunakaran, J. Mukherjee, B. Ramalingam and C. A. Biggs, Appl Microbiol Biotechnol, 2011, 90, 1869-1881.

97. R. Alvarez, A. J. Burdette, X. Wu, C. Kotanen, Y. Zhao and R. A. Tripp, Rapid Identification of Bacterial Pathogens of Military Interest Using Surface-Enhanced Raman Spectroscopy, DTIC Document, 2014.

98. P. N. Sampaio, B. Cunha, F. Rosa, K. Sales, M. Lopes and C. R. Calado, 2015.

99. H. Zhou, D. Yang, N. P. Ivleva, N. E. Mircescu, S. Schubert, R. Niessner, A. Wieser and C. Haisch, Anal. Chem., 2015, 87, 6553-6561.

100. A. A. Bunaciu, H. Y. Aboul-Enein and Ş. Fleschin, Appl. Surf. Sci., 2015, 50, 176191.

101. U. Neugebauer, S. Trenkmann, T. Bocklitz, D. Schmerler, M. Kiehntopf and J. Popp, J. Biophotonics, 2014, 7, 232-240.

102. W. Premasiri, D. Moir, M. Klempner, N. Krieger, G. Jones and L. Ziegler, J. Phys. Chem. B, 2005, 109, 312-320.

103. P. Zarnowiec, L. Lechowicz, G. Czerwonka and W. Kaca, Curr. Med. Chem., 2015, 22, 1710-1718.

104. M. J. Riding, F. L. Martin, J. Trevisan, V. Llabjani, Patel, II, K. C. Jones and K. T. Semple, Environ. Pollut., 2012, 163, 226-234.

105. K. A. Heys, M. J. Riding, R. J. Strong, R. F. Shore, M. G. Pereira, K. C. Jones, K. T. Semple and F. L. Martin, Analyst, 2014, 139, 896-905.

106. J.-X. Cheng and X. S. Xie, Science, 2015, 350, aaa8870.

107. L. Cui, P. Y. Chen, B. F. Zhang, D. Y. Zhang, J. Y. Li, F. L. Martin and K. S. Zhang, Water Res., 2015, 87, 282-291.

108. Z. Movasaghi, S. Rehman and D. I. ur Rehman, Appl. Surf. Sci., 2008, 43, 134-179.

109. S. Kumar, T. Verma, R. Mukherjee, F. Ariese, K. Somasundaram and S. Umapathy, Chem. Soc. Rev., 2016, 45, 1879-1900.

110. J. Li, R. Strong, J. Trevisan, S. W. Fogarty, N. J. Fullwood, K. C. Jones and F. L. Martin, Environ. Sci. Technol., 2013, 47, 10005-10011.

111. E. K. Costello, C. L. Lauber, M. Hamady, N. Fierer, J. I. Gordon and R. Knight, Science, 2009, 326, 1694-1697.

112. C. L. Lauber, M. Hamady, R. Knight and N. Fierer, Appl. Environ. Microbiol., 2009, 75, 5111-5120.

113. P. Marschner, C.-H. Yang, R. Lieberei and D. Crowley, Soil Biol. Biochem., 2001, 33, 1437-1445.

114. M. Wietz, B. Wemheuer, H. Simon, H. A. Giebel, M. A. Seibt, R. Daniel, T. Brinkhoff and M. Simon, Environ. Microbiol., 2015, 17, 3822-3831.

115. S. M. Ede, L. M. Hafner and P. M. Fredericks, Appl Spectrosc, 2004, 58, 317-322. 
116. M. R. Brown, D. G. Allison and P. GILBERT, J. Antimicrob. Chemother, 1988, 22, 777-780.

117. O. Fridman, A. Goldberg, I. Ronin, N. Shoresh and N. Q. Balaban, Nature, 2014, 513, 418-421.

118. C. G. Mayhall and E. Apollo, Antimicrob. Agents Chemother., 1980, 18, 784-788.

119. C. G. Xie, D. Chen and Y. Q. Li, Optics Letters, 2005, 30, 1800-1802.

120. K. Kogermann, M. Putrins and T. Tenson, Eur. J. Pharm. Sci., 2016, 95, 2-16.

121. J. Trevisan, P. P. Angelov, P. L. Carmichael, A. D. Scott and F. L. Martin, Analyst, 2012, 137, 3202-3215.

122. W. B. Whitman, D. C. Coleman and W. J. Wiebe, Proc. Natl. Acad. Sci. U.S.A., 1998, 95, 6578-6583.

123. Y. Song, A.-K. Kaster, J. Vollmers, Y. Song, P. A. Davison, M. Frentrup, G. M. Preston, I. P. Thompson, J. C. Murrell and H. Yin, Microb. biotechnol., 2017, 10, $125-$ 137.

124. T. Chen, C. Cao, J. Zhang, A. M. Streets, Y. Huang and T. Li, bioRxiv, 2017, 121616.

125. K. R. Jonscher, A. Alfonso-Garcia, J. L. Suhalim, D. J. Orlicky, E. O. Potma, V. L. Ferguson, M. L. Bouxsein, T. A. Bateman, L. S. Stodieck and M. Levi, PLoS ONE, 2016, 11, e0152877. 